\title{
'If my sign could speak': The Signboard and the Visual Culture of Early Modern London
}

\section{The place of the sign}

Some years ago the influential critic W.J.T. Mitchell turned his attention to the interrelation of word and image, observing that: 'The history of culture is in part the story of a protracted struggle for dominance between pictorial and linguistic signs, each claiming for itself certain proprietary rights on a "nature" to which only it has access'. ${ }^{1}$ Mitchell's work centred upon the construction of critical discourse on art and literature since the eighteenth century, yet his comments can prove equally productive for considering critical approaches to early modern drama. Mitchell is resistant to the notion of a master theory of signs that would embrace literature and the plastic arts together as equivalent operations, pointing instead to the encounter between word and image as a potentially dynamic site for the production of meaning. This essay concerns itself with just such a point of encounter, focusing upon the signboard as deployed in early modern drama. Drama, with its mingling of verbalised text and visual spectacle, is of course a medium predisposed towards the exploitation of this encounter, and the signboard, with its surprisingly insistent presence in the dramatic texts of the period, provides an important index to the modes of early modern visual-verbal imagination. In what follows I suggest that the signboard presented a potent source for the production of meaning which resists easy codification for the cultural critic of today as it did for the writers of the early modern period. What characterises the signboard of the city for the urban inhabitant is after all its very availability to a host of different interpretative strategies. What marks it out for the critic is a consequent superfluity of meaning, and an irreduceability to textual formulae. The signboard then, stands at a blindspot in the textual coverage of the early modern imagination.

To understand the uses of the signboard in early modern literature it is necessary to enquire first into the process of signboard signification. From 
the medieval period there are references to houses noting sculpted signs affixed to the exterior, and emblematic trade signs are also recorded, but it appears that taverns were to the forefront in the more systematic adoption of painted signboards - a practice sustained by subsequent regulatory stipulations. ${ }^{2}$ Just how did the signboard operate in the early modern city? At the heart of the difficulties for the modern day reader of conceptualising the role of signs in early modern culture is precisely the temptation, noted by Mitchell, to posit an equivalence between visual and textual signification. Hence, for example, filmic attempts to reconstruct the urban environment of sixteenth-century England have often erred in allowing the textual nomination to predominate over a visual image where signboards are concerned. The memorable moment in Michael Curtiz's epic The Private Lives of Elizabeth and Essex where a desperate Francis Bacon enquires the route to London at a tavern whose signboard features alone the textual legend 'The Red Lion' is a notable case in point. Such moments of anachronistic reconstruction may run counter to our knowledge of levels of literacy in the period, but more importantly they undertake a fundamental reconfiguration of the relationship between the signboard and the building which writes out of history the interpretative agency attendant upon the image based sign. The text announces the nomination of the building in question, presenting it as already inscribed with meaning. In doing so it collapses the space between the signboard itself and the tavern - a space of interpretative play which I contend was more readily apparent in the early modern period and which I want to excavate here in various ways.

Contrast Curtiz's reconstruction of early modern culture with the suggestive remarks contained in a satirical character of a painter published in 1631 . Debating the subject of an alehouse sign with his patroness, the painter advocates the following image: 'A Lyon, sayes he, for that's the onely Signe that he can make. And this he formes so artlesly, as it requires his expression: This is a Lion'. ${ }^{3}$ The technique of satirizing a painter's artlessness and lack of ability through the limited repertoire and ambition of a signpainter seems to have been commonplace. Jonson spoke of 'A painter who could paint nothing but a rose, [who] when an inn-keeper had advised him about an ensign, said that a horse was a good one, so was a hare, but a rose was above them all'. ${ }^{4}$ In each case the joke speaks to a familiar repertoire of visual imagery and connotes highly standardized acts of representation. Importantly the failure of the first painter to perform even this operation is so marked that it requires the textual explication to control its interpretation. Despite this, however, the text does not proclaim a textual name for the tavern, but refers us back to the 
image in a move which acknowledges the primary importance of visual signification. ${ }^{5}$ The text intervenes in the reading of the image rather than subsuming it. So while the satire works upon the expectation that this subject, then as now one of the most common of inn signs, is part of a limited vocabulary of conventionalized image-based signs, it nevertheless denies the equivalence of word and image.

Where today we are accustomed to referring to buildings, pubs, and other sites by their verbal names, of which the inscription over the door or in a guidebook stands as no more than a particular citation, textual evidence of the early modern period repeatedly alludes to taverns and other buildings 'at the sign of. Such a usage, current from at least the beginning of the sixteenth century, draws attention to the signboard both as the focus for interpretative activity and, vitally, as a spatial reference point from which the location of the building is derived. The building stands as secondary to the signifying activity of the sign. Even where no sign is overtly mentioned I would suggest we ought to infer the silent presence of a sign projecting into the street and actively encoding the building in question. Peter Clark has noted the increasing use of ever more costly signs replacing the traditional ale-stakes at country taverns and inns in the late sixteenth century. ${ }^{6}$ In London signboards seem to have been in use from much earlier - the Liber Albus of 1419 records an article of fifty years before, regulating the length of tavern ale-stakes that are adorned with the tavern-keeper's 'sign or leaves' . In John Taylor's 1630s textual exploration of well over three hundred taverns in London discussed below only two were described as having a bush but no sign, demonstrating not only how widespread the practice was, but further how the sign determined the identity of the tavern; these taverns had no other name. So predominant is the influence of the sign over the building in this regard that we find such curious constructions as Henry Machyn's reference in the mid-sixteenth century to 'the wyff of the syne of the Rose'. ${ }^{8}$ In Machyn's phraseology the tavern is subsumed within a metonymic figuration which underlines the prominence of the sign in both the physical and the conceptual world of the early modern citizen.

As an important fixture of the urban environment the signboard is vitally implicated in the process of spatial conceptualization of the city. References to buildings 'at the sign of postulate the sign as a quasi-autonomous entity within the space of the city from which the tavern derives its nomination by a relationship of proxemics. As such the sign is available for referential use in neighbouring areas beyond the nucleus of signboard and tavern. Hence in Stow's Survey of London we find repeated references to places named 'of such 
a signe' whereby the sign appropriates or is appropriated by a broader constituency. Thus we read: 'Next adioyning to this Royall Exchange remaineth one part of a large stone house, and is now called the Castell of such a signe, at a Tauerne doore'. ' Whether the tavern occupies part of the building or is simply adjacent to it, this is one of a number of examples Stow records where formerly stately residences are broken up into parcels and redesignated by the presence of tavern signs. Equally streets and areas as well as buildings take their name from the presence of signs. So we find 'Greenewitch lane of olde time so called, and now Frier lane, of such a signe there set up'. ${ }^{10} \mathrm{~A}$ signboard, without reference to a tavern or any other building to which it might be understood principally to pertain, again overrides a name for which Stow has found precedent historical evidence. On occasion the derivations offered by Stow may be open to challenge but they do serve to illustrate the conceptual force accorded to the sign within the urban environment. In fact such is the strength of association between the image-based sign and the designation of a location that when the sign is not the predominant vehicle for ascription it demands special comment. Thus of Three Cranes Lane Stow informs the reader that it is 'so called not onely of a signe of three Cranes at a Tauerne doore, but rather of three strong Cranes of Timber placed on the Vintrie wharfe by the Thames side, to crane up wines there'. ${ }^{11}$ The unusualness of a mimetic sign with adjacent referent is evident in this description and emphasizes the expected autonomy of the visual sign. Even in this case the particularity of the derivation from the immediate locale is somewhat undermined by the fact that at least seven taverns by the sign of the Three Cranes existed in the city. Nor does Stow go so far as to make the actual cranes the sole source for the naming of the lane. The telling phrase 'not onely of a signe' acknowledges that the signboard cannot be completely written out of the equation between location and ascription.

Stow's Survey of London is a text deeply hostile to the kind of privatized and licentious indoor activities represented by the tavern, preferring to celebrate throughout the wholesome virtues of traditional outdoor activities. The fact that inn and tavern signs figure so frequently in the Survey is thus testimony to the wider role they play within the cultural experience of the urban environment. The taverns and inns of the city appear not as invitations to indoor impropriety, but insofar as they operate within the consciousness of Londoners past and present as a key resource in negotiating and deciphering the spaces of the city, an operation in which it is the signboard which predominates. 
If signs exert an influence in naming areas of urban space, they also play an important role in the navigation of the metropolis. In a city where street names were subject to alteration and street numbers were still several hundred years off, signs presented a key resource for local orientation. Yet in contradistinction to the totalising operations of cartography that would receive so massive an impetus in the aftermath of the Great Fire, navigation by signboards is founded upon engagement with the city as a social entity. ${ }^{12}$ Signboards operate as orientational material at a strictly local, neighbourhood level and presuppose social interaction to be fully effective. A playful conversational model provided in a 1593 French primer illustrates the interrogative process of sign navigation:

Where dwelleth the ordinarie post to Calis, to Bruges, to Antuerpe ?

He dwelleth in the Iewrie.

At what signe?

At the white Lyon, at the grenning Iackanapes.

Is it not right over against the Vnicorne?

It is a little further, on this side the Goate and the red horse, iust over against the blacke Bull, neere the Dogs head in the pot. ${ }^{13}$

The multi-optional dialogue delights in the copious generation of a sign menagerie. In the process it suggests the symbolic surplus produced by signboards which complicates their representation under cartographic symbols. What cartographic sign could adequately represent the self-consciously symbolic signboard? Equally both the repetition of particular signs in diverse parts of the city and their negotiational use within the practice of everyday life ensure that signboards do not translate into features of cartographic representation. Despite their spatial presence within the city, cartography overlooks these symbols located at precise points, in favour of the representation of quantified areas punctuated by synchronic networks of streets. The cartographic sign which promises to stand in place of the site represented, and to offer a mathematical articulation of its location, effects the erasure of both the need for and the evidence of these free-standing symbols in their capacity as orientational markers.

If cartography will not accommodate the spatial operations of the signboard, these prove equally difficult to systematize within a textual format. The most direct attempt to perform this difficult operation I have come across occurs in a manuscript description of London dating from around 1620.14 Setting out to provide a textual navigation of the longitudinal axis of London from the Palace of St James to the Tower, the 'author' moves from a densely 
formatted textual introduction to a schematic organization on the model of an itinerary or rental. Listing significant buildings and tavern signs to be seen on each side of the street down each side of the paper s/he cites over fifty-six signboards in the space between St James' and Ludgate. The organization of the text is clearly intended to reproduce the orientational process of a journey and not simply to list noteworthy sites since it uses centralised linking texts to describe the visual vantages of certain points as with 'over against this | howse you maie stand | and see charing' - that is, Charing Cross. ${ }^{15}$ Emphasis on what can be seen, then, combined with a textual navigation presents a textual environment in which the prominence of the signboard emerges insistently from the page. Yet the level of spatiographic gymnastics required of the writer to provide and sustain a textual container for signboard orientation seems ultimately to have proved too much for the author to deal with. The spatial narration breaks off at Ludgate Hill only a few yards inside the city gates with the densely signed centre of the city still unencompassed.

The concentrated, radial nature of signboard signification, its rootedness within spatial experience, as well as its visual component account for the elusiveness of the signboard environment and for the scarcity of attempts to record it systematically. When Wasp says of Master Cokes in Bartholomew Fair that 'he would name you all the signs over, as he went, aloud' (4.1.109-10), his statement is itself a sign of his master's disoriented drifting amongst the distractions of London. ${ }^{16}$ Cokes's actions have a real life parallel in the more deliberate but equally detached project undertaken by Philip Howard. A contemporary memoir records how:

Going one day from the Cathedrall Church of St Paul in London to his own house without Temple Bar, he observed the signs of all the houses that were on the left side of the street, which are some hundreds questionless, and being come into his house he caused one of his servants to write them down in a paper as he named them and another being sent with the paper to try thereby if the signs of the houses did agree both in name number, and order with those written in the paper, found them exactly so to do. ${ }^{17}$

Howard's venture may produce a paper record that is proved against the evidence of the city's signscape, but the anecdote is reported specifically as testimony to Howard's prodigious memory, alongside his ability to memorize passages of classical history at a single hearing. The very noteworthiness of the feat thus lies in its abstraction from the conceptual resources of urban spatial 
cognition and as such speaks to the difficulty of translating modes of spatial experience into textual or cartographic systematizations of knowledge.

If the navigational networks within which the signboard operates prove resistant to both cartographic and textual representations of space, we find in the works of John Taylor an attempt to systematise the signboards along somewhat different lines. In the late 1630s Taylor produced several texts which draw upon his researches into the signs and taverns of the city. Most notable of these is the fulsomely titled Taylors Travels and Circular Perambulation through, and by more then thirty times twelve Signes of the Zodiacke of the Famous Cities of London and Westminster. Despite the reference to the textual trope of perambulation, Taylor's opening section reports on, rather than textually performing, the negotiation of urban space. The governing conceit is centred rather on the symbolic coherence of a sign system. Modelling itself upon the progression of the sun through the signs of the zodiac Taylors Travels alleges, occasionally somewhat tortuously, equivalences between groups of signboards and the astrological symbols - although the Crab eludes him 'except in the crabbed frowne of a womans face'. ${ }^{18}$ As an organizational framework the zodiac has the advantage of coupling a representational code with a spatio-temporal motion that presents at least the potential for a harmonization of sign imagery; however the dream of a regulated order of signs is exploded even as it is announced by the excessive potential of the material on offer: 'So I, in Imitation of the Sunne, have in one Moneth progress'd through London, Westminster, with the Suburbs, and the Burrough of Southwarke, not as the Sunne doth through twelve, but neer thirtie times twelve Signes'. ${ }^{19}$ Taylor's progression surpasses the astrological code not merely in temporal compression and the number of equivalences he is able to uncover for the twelve signs, but in the superfluity of signboards which exceed the constraints of classification - where exactly are the signs of the Garter or the Turnstile to figure in this constellation? In the end his text adheres only to a covert mathematical symmetry, recording some three hundred and sixty five signs within the City. Taylor in fact abandons the projected cohesion of the zodiacal conceit, devoting the remainder of his text to an alphabetical subject grouping of the city's signboards accompanied by a series of epigrams. Dedicated to the Vintners' Company, Taylor's verses play upon connections between the sign image and the effects of the alcohol available within the tavern, generally by stressing the artificiality of the image and transposing the qualities of the subject depicted onto the tavern fare. Hence the epigram relating to the six Greyhound Taverns in the city: 
These Greyhounds nere hunt Buck, nor course a Hare

Instead of hunting, they still hunted are:

And those that hunt them many times are bit,

Lam'd in the Leggs, and Creepl'd in their VVit. ${ }^{20}$

But occasionally the subject matter touches on more highly charged aspects of contemporary culture, as with the epigram on the four Pope's Head signs.

These Popes heads are no Authors of Debate,

Nor Schismaticks, or Troublers of the State:

Yet theres good Claret, and Sack Catholike

Will make a Mad man Tame, a Tame man strike. ${ }^{21}$

Denigration of the Pope might not appear the most radical interpretative activity to undertake, but it does suggest the potential residing in the signboard culture of the city for more pointedly contentious readings.

Amidst the social and religious tensions of the mid-century this potential came to be realised. By 1665 Richard Flecknoe could safely mock in print the fanatical reformers who cried out against 'the Signs in the City ... as the abomination of abominations, to see so many Popes-heads, so many TripleCrowns, Bishops Miters, and Cardinals Caps, with Friars and Nuns, Beads, Agnus Dei's, and the like, which makes London look like a very Babylon'.22 If Flecknoe's comments sound hyperbolic, they are lent weight by the report of Taylor himself, who recorded elsewhere the transformation of such signs as the Salutation (a reasonably common tavern sign depicting the Angel saluting the Virgin Mary) into the two Gallants, wryly noting that 'Signes subject are to mutability'. ${ }^{23}$ Taylor was keenly aware of how the symbolic charge of a signboard might take on specific resonances in such a context. Commenting on the shelter he found at the tavern of the King's Arms in Bellinshurt, whose sign had earlier been literally targeted by Parliamentary troops, he appropriated the image to the terms of Royalist regret, lamenting that 'armes are of no use without a Head'. ${ }^{24}$ Taylor, whose brother kept the tavern of the King's Arms in Abingdon, became more directly involved in the use of signboards as a form of cultural intervention when he took over the tavern at the sign of the Crown in Phoenix Alley in the late 1640s. Following the execution of Charles I, his royalist sympathies were apparently expressed in converting the sign to that of the Mourning Bush. ${ }^{25}$ Such an overtly subversive deployment of the signboard's potential could not pass unchallenged and he was obliged to replace the image, selecting in its stead an image of his own head. In the pamphlet published to commemorate the occasion he deftly played upon the 
multiple resonances of these actions, figuring the change as a transposition of resistance into both a state of mind and a literary project in terms representative of a number of royalist writers in the period: 'The Crown's transformed,/ into the Poets Head ${ }^{26}$ As the sign at which Taylor traded both as tavern keeper and seller of his own books, the sign of the Poet's Head is mentioned in the colophon of his late publications, reinforcing the covert sense that the sign of his allegiance is now displayed in the production and dissemination of print. ${ }^{27}$

In Taylor's deployment of signs, then, we recognise the potential for appropriating the signboard within symbolic acts of resistance. To realise that we ought to accord the manipulation of sign imagery a greater level of cultural resonance, we need only remember the case of the merchant Burdet, executed by Edward IV for publicly announcing that he would make his son heir to the Crown, the sign at which he traded. Whether we see this action with the chronicler Edward Hall as evidence of the king's misconstruction - a reading evoked by Shakespeare's Richard III to persuade the citizens against Edward's line - or, alternatively, as an overtly subversive speech act, it underlines the symbolic charge that could attach to the operation of signs. ${ }^{28}$

\section{The sign and the stage}

In the texts discussed so far we have witnessed the registering of the sign's spatial, nominational, and representational potential and encountered the difficulties of making these operations cohere textually. The copious capacity of the signboard to figure simultaneously within a plurality of correspondences between space, community, person and indeed between signboards themselves, makes them resistant to textual systematization. In turning now to the uses of the signboard within early modern drama, we focus upon an institution actively concerned with drawing together and exploiting the range of signifying practices which animate the potentiality of the sign. The public theatres of the early modern period were of course themselves located at the signs of the Rose, the Curtain, the Swan, et al., and inns at such signs as the Bell Savage and Cross Keys continued to host playing companies into the 1590s. ${ }^{29}$ Upon the stages of these venues the signboard was extensively deployed as a theatrical sign in both physical and metaphorical terms. Drama of the period frequently engages closely with the conventional subjects of signboard representation; hence, for example, the considerable number of references to the sign of St George and the Dragon, whose generic features are rehearsed in The London Prodigall in a direct address to the sign itself: 
A, haue we spide you stout $S$. George?

For all your dragon, you had best selles good wine:

That needs no yuie-bush, well, weele not sit by it,

As you do on your horse. ${ }^{30}$

The evidently familiar image of chivalrous valour is applied to the quixotic bravery of Puntarvolo in Every Man Out of his Humour, where Carlo describes his appearance on horseback: 'he looks like the sign of the George, that's all I know - save that instead of a dragon, he will brandish against a tree' $(2.1 .145-7) .{ }^{31}$ Beyond the currency of the visual image, the sign was clearly conventional enough as a figure for nationalized knightly virtue for Strozzo's rhetorical comparison, 'like the English signe of great Saint George' in Chapman's The Gentleman Usher to attract the aside 'A Plague of that Simile' (1.2.93-4). ${ }^{32}$ The idea of imitating the sign is taken to its furthest conclusion in the pamphlet history of The Life and Death of the merry Devill of Edmonton - closely related to the corrupted text of the play of the Merry Devil of Edmonton - when Smug evades his captors by climbing upon the sign of the White Horse thus converting the image to that of the George and convincing his pursuers they have taken a wrong turning to Hodsdon. ${ }^{33}$

The sign of the George clearly constituted part of the audience's visual imagination and was thus readily available for citation, or adaptation onstage. For the early modern theatre a major factor in the signboard's symbolic freighting lay in its free availability to interpretative agency. So in The First Part of the Contention of the Two Famous Houses of York and Lancaster (Henry VI, Part Two) Margaret attacks Henry's mourning of the death of Gloucester by challenging him to 'Erect his statue and worship it, / And make my image but an alehouse sign' (3.2.80-1). The contrast is not confined to the status attaching to the site - Gloucester's tomb monument opposed to the alehouse, the lowest form of hostelry - but extends to the manner of reading that appertains to each. Gloucester's statue is to be reverentially regarded, in a form eliciting a particular manner of response, but Margaret's image is to become accessible to a multiplicity of potential readings unconstrained by any rhetoric of veneration.

Central to the distinction which Margaret makes is the contrast between the embodied image of Gloucester in the form of a statue and the flat artificiality of the signboard, a theme which John Taylor's verse upon the signs of the Queen's Head itself plays upon:

These Queenes heads like the Kings heads are, I see

Both are one Sex, both Wood, both Painting be. ${ }^{34}$ 
Taylor's deconstruction of the operation of visual imagery into its component materials was composed prior to his own active involvement with the heads of monarchs, but its emphasis upon the literal superficiality of two-dimensional visual signification suggests the rich potential for play upon the separation of image and referent, contrasting surface impressions with substantive actions. So in Titus Andronicus Aaron chastizes his 'sanguine shallow-hearted boys,' as 'ye alehouse painted signs' (4.2.96, 97), made of no sterner stuff than paint, and Margaret is transformed into the common image of a queen but denied the attendant attributes of monarchy. Playing on the practice of the taking down of the sign (or the bush, its earliest forerunner) at the closure of a tavern, Fletcher's Wit without money makes similar play upon this separation when in the mouth of the pithy Shorthose the sign becomes the indicator of an evacuated presence. Assessing the character of Francisco he tells us: 'He's a begger, only the sign of a man, the bush pull'd down, which shows the house stands emptie' (2.3.12-14). ${ }^{35}$

In the stress upon the artifice of signification we find evidence of the early modern theatre's concern with the process of interpretation itself; the activity of reading the visible world comes under scrutiny through the investment in the signboard image. So rather than highlighting duplicitous manipulation of the sign, the Duke in Fletcher's Rule a wife, have a wife questions the accepted interpretation of Leon by challenging the errors of a superficial popular reading, asking incredulously

Is this the Fellow that the People pointed at,

For the meer sign of man, the walking Image?

He speaks wondrous highly.

The evidence of verbal facility dispels the visually derived image; the word is proffered here as the more reliable signifier.

The attack upon the 'mere sign' is predicated upon the demand for correspondence which manifests itself in an investigation of the perceived claims of signification which the stage is only too ready to rehearse. The ability to read the signs is precisely the professional claim of the group of almanac writers we witness in Thomas Nabbe's Presentation who set out to test their credit in a series of astrological taverns, pronouncing: 'Wee'le try all the houses in the Zodiac; and if they will not trust, wee'le pull downe the signes'. ${ }^{37}$ The authority of these professional interpreters is doubly undone as they gain no credit at the Signe of the Moone, 'the rendezvous of our fraternitie', aptly epitomising the failings of their fraudulent mis-reading of the stars which the play lambasts as untrustworthy. Like Taylor before him, Nabbes's deploy- 
ment of the zodiac schema doesn't hold, and his troop of almanac writers exposes the dangers of credulous passivity in the activity of interpretation.

Although Nabbes's piece suggests a certain anxiety over signboard interpretation, the early modern stage is in general more inclined to seize upon the potential of the signboard to generate correspondences than it is eager to negate signification. Later editions of Heywood's Rape of Lucrece feature a sign song in which a series of inn signs attract appropriate followers, illustrating the kind of sign significance often upheld onstage: 'The Church-man to the Miter./The Shep-heard to the Starre./The Gardiner, hies him to the Rose,/ To the Drum the man of warre. ${ }^{38}$ Alongside invocation of the sign in this manner we also find frequent instances in which the sign features as a site of interpretative agency. A typical opportunity for the discussion of sign readings is provided by the planning and construction of a sign. Thus in Nabbes's Covent Garden, the host rejects his client's suggestion of the Loggerheads for the sign of his tavern, substituting this joke at the expense of his customers for the image of a balance weighing wine against gold and jewels - simultaneously encoding both 'the value of good Wine', as one customer points out, and its cost. ${ }^{39}$ The plotting of Able Drugger's sign in The Alchemist and the inquiry into the intentions behind the Sign of the Cheat Loaf in Middleton and Rowley's A Fair Quarrel exploit parallel concerns of the shop and inn sign with both attracting customers and producing a personalized public marker. ${ }^{40}$ In Haughton's An Englishman for my money, or ... A Woman will have her will, the author satirically deploys this function of the sign as the public statement of a personal ethos when a persistent foreign suitor attempts to gain late-night access to his would-be lover but finds himself instead suspended in a basket above the door to the premises. His hanging there, which is explicitly in place of a sign, neatly embodies the claims of a woman to control her involvement in the marriage market announced in the subtitle. ${ }^{41}$

Of all the early modern writers to engage with the culture of the visual sign it is Ben Jonson who provides some of the richest examples of staging the signboard. In the case of his 1622 Masque of Augurs this consists of a very literal staging when the companions of 'The Three Dancing Bears' alehouse supervise a performance of three bears who 'dance to present the sign, and the bear ward to stand for the signpost'. ${ }^{42}$ Most productive of all Jonson's involvements with the visual sign, however, is The New Inn which centres upon the activities taking place at the Light Heart in Barnet. In this play the signboard takes a central, defining role, and as its most recent editor has rightly pointed out, must have hung onstage throughout the performance. ${ }^{43}$ The 
image itself, constructed as a double rebus, depicts on the one side a feather outweighing a heart, denoting the name of the inn, on the other a bulging purse, two turtles and a heart with a torch protruding from it signify the moral 'a heavy purse makes a light heart'. The rebus is of course a visual sign that transposes a verbal formulation - Abel Drugger's sign, in The Alchemist is a particularly tortuous example of Jonson's use of one. But I believe we misread its significance if we regard the image as dispensable and operate solely with the verbal formula. '[I]f my sign could speak' (1.1.2.), conjectures the host, reminding us that its signification is not reduceable to words. As has recently been noted, Abel Drugger's sign invokes the figure of the Bellman of London, a visual image familiar from woodcut illustrations but long obscured by critical emphasis on the verbal bias of the rebus. ${ }^{44}$ Equally in The New Inn, the image of the Light Heart resonates with the conceptual linkages which I have suggested attach to the signboard in early modern culture. Jonson's sign of the Light Heart is figured throughout the play as both the governing property of the innkeeper Goodstock (or Lord Frampul, as he later reveals), and as governing principle of the inn itself. When the disposition of the melancholy Lovel threatens to jeopardize the correspondence between sign and tavern, Goodstock seeks to preserve the integrity of the sign:

If you have a mind to be melancholy and musty,

There's Footman's Inn at the town's end, the stocks,

Or Carrier's Place at sign o'the Broken Wain.

The correspondence of sign and signifier represented by the inn sign is sufficiently strong to sustain a metaphorical transposition. Lovel even configures his own early melancholia in the guise of a sign, describing himself in terms of a negative but not negated correspondence as 'The most unprofitable sign of nothing'(1.6.88). Similarly, in words which recall the treasonous construction of Burdet, the Light Heart is presented as both a quality and a property of the inn keeper, to be transferred to his next of kin, who remarks

I do

What, madam, I am designed to by my birthright;

As heir of the Light Heart, bid you most welcome.

Even when Goodstock is unveiled as Lord Frampul and his heir Frank is revealed to him as his daughter Laetitia, the signboard does not lose its credibility amongst the play's deceptive surfaces. The essential qualities designated by the signboard remain those that characterize the superficially transformed relations. Present throughout onstage the significance of the sign 
endures as a persistent reminder of the way in which early modern drama deployed signifying practices beyond the verbal.

In the course of this investigation of the signboard and its uses for early modern drama I have sought to highlight the capacities of a resource that re-establishes the rootedness of the drama in the cultural experience of its period. For literary critics, working outwards from the textual trace, it is all too easy to generate verbo-centric conceptions of the way early modern culture operated. The signboard, an everyday visual artefact firmly fixed in the notion of presence, and one focusing attention upon the activity of signification, can stand for us as a fixture pointing back to the interpenetration of verbal and visual in the early modern imagination. As an instance of visual culture transported onstage the signboard can continue to indicate the rich stock of supra-verbal imagery and association available to the drama. As a figure for signification itself, the signboard offered the potential for an investigation of the theatre as process. Finally, as a trope both verbally invoked and physically imported into the stage worlds of the period, the signboard reveals the fluidity and productivity of the encounter between word and image. Jonson's design in The New Inn, I would suggest, involves structuring and exploiting the recognised potential of the signboard within early modern culture and in Goodstock's defiant cry 'I will maintain the rebus 'gainst all humours' we find the mediated means through which that capacity comes down to us (1.1.9.).

\section{Notes}

An early version of this article was first aired at conferences in London and Reading and I am grateful to the organizers, Patricia Brewerton, Stephen Clucas and Adam Smyth. I would also like to thank the following people for their comments: Michael Bath, Mark Hutchings, Helen Ostovich, Tom Rist, and Robert Tittler.

1 W.J.T. Mitchell, Iconology: Image, Text, Ideology (Chicago, 1986), 43.

2 David Garrioch, 'House names, shop signs and social organization in Western European cities, 1500-1900', Urban History 21 (1994), 20-48, 46. The requirement for tavern signs is cited in Jacob Larwood and John Camden Hotten, The History of Signboards (London, 1866), 10. On the shop signs of the period see also Ambrose Heal, The Signboards of Old London Shops 
(London, 1947) and Philip Norman, London Signs and Inscriptions (London, 1897).

3 Richard Brathwait, A Cater-Character throwne out of a Boxe By an Experienc'd Gamester (London, 1631; STC 3591), 15, sig.L5.

4 'Conversations with William Drummond', Ben Jonson: The Complete Poems, George Parfitt (ed.) (Harmondsworth, 1996), 11.504-7.

5 In a satirical verse on the poet Wilde later in the seventeenth century we find Alexander Radcliffe similarly maintaining the integrity of the visual sign despite the failings of the practitioner when he speaks of 'Ill Painters [who] when they make a Sign /... I Do never think it any shame / To underwrite the Creature's name', in The Ramble (London, 1682; STC: R129), 85.

6 Peter Clark, The English Alehouse: A Social History 1200-1830 (London, 1983), 67-8.

7 Liber Albus: The White Book of the City of London [1419], H T. Riley, trans. (London, 1861), 389; cited by Larwood and Hotten, The History of Signboards, 6.

8 The Diary of Henry Machyn, Citizen and Merchant-Taylor of London, from A.D. 1550 to A.D.1563, John Gough Nichols (ed.) (London, 1848), 304.

9 John Stow, A Survey of London (1603), C.L. Kingsford (ed.) (Oxford, 1908), $1: 193$.

10 Stow, Survey, 1:231-2.

11 Stow, Survey, 1:239.

12 On post-Fire advances in the cartographic representation of London see Andrew Gordon, 'Performing London: The map and the city in ceremony', Literature, mapping and the politics of space in early modern Britain, Gordon and Bernhard Klein (eds).(Cambridge, 2001), 69-88, and Cynthia Wall, The Literary and Cultural Spaces of Restoration London (Cambridge, 1998), 39-111.

13 John Eliot, Ortho-Epia Gallica, Eliots Fruits for the French (London, 1593; STC: 7574), book 2, 27-8.

14 Larwood and Hotten make reference to this manuscript, citing the names of the inns and taverns included, but fail to grasp its spatial format alleging first that it covers the area from Charing Cross to the Tower, and subsequently that the 'the good citizen' begins at Whitechapel and progresses to the Tower. Neither statement is accurate. See History of Signboards, 8-9.4

15 'Description of London', BL Harley ms 6850 f.31.

16 Ben Jonson, Bartholomew Fair, E. A. Horsman, (ed.) (Manchester, 1979).

17 The Lives of Philip Howard, Earl of Arundel, and of Anne Dacres, His Wife. Edited from the Original Mss, The Duke of Norfolk [H.G.F. Howard] (ed.) (London, 
1857), 128. I am grateful to Professor Michael Bath for supplying me with this reference.

18 John Taylor, Taylors Travels and Circular Perambulation through, and by more then thirty times twelve Signes of the Zodiacke, of the Famous Cities of London and Westminster (London, 1636; STC 23805), A3v.

19 Taylor, Taylors Travels, A3r-v.

20 Taylor, Taylors Travels, B8r.

21 Taylor, Taylors Travels, C8r.

22 Richard Flecknoe, Aenigmaticall Characters (London, 1665; Wing F1214), 83.

23 Taylor, Of Alterations strange (London, 1651; Wing T493A), 10.

24 Taylor, The Certain Travailes of an uncertain Journey (London, [1654]; Wing T438), 12.

25 Bernard Capp, The World of John Taylor the Water-Poet, 1578-1653 (Oxford, 1994), 155.

26 Taylor, Of Alterations strange, title page. On the strategic literary responses of royalist writers to the events of the 1640s and 50s see particularly Lois Potter, Secret rites and secret writing: Royalist literature, 1641-1660 (Cambridge, 1989), 72-112, and James Loxley, Royalism and Poetry in the English Civil Wars: The Drawn Sword (Basingstoke, 1997), 210-34.

27 Jeffrey Masten has recently speculated on the meanings generated by the use of Ben Jonson's Head as a book shop sign in the late 1650s, linking it to the emergent concepts of authorial difference. Given Jonson's importance to royalist writers of the period, as well as Fletcher's, the other authorial head cited by Masten, I would speculate on a potential rhetoric of royalist identity here, which Taylor whose sign was well enough known to be remembered by Aubrey - may well have been the originator of. Jeffrey Masten, 'Ben Jonson's Head', Shakespeare Studies 28 (2000), 162-8.

28 For Hall, see Narrative and Dramatic Sources of Shakespeare, G. Bullough (ed.) (London, 1960), 3:273. For Shakespeare, see Richard III, 3.5.74-77 in The Complete Oxford Shakespeare, Stanley Wells and Gary Taylor (eds) (Oxford, 1987). All further references are to this edition.

29 Andrew Gurr, The Shakespearean Stage 1576-1642 (Cambridge, 1980), 113-24.

30 Anon., The London Prodigall (London, 1605; STC: 22333), B2r. Evidently the sign of the George must have been displayed onstage during this scene.

31 Jonson, Every Man Out of His Humour, Helen Ostovich (ed.) (Manchester, 2002). 
32 In The Plays of George Chapman: The Comedies, Allan Holaday (ed.) (Urbana, 1970).

33 The earliest extant copy of the pamphlet dates from 1631. On the corruption of the text of The Merry Devil of Edmonton see the editions of W.M. Adams (Durham, SC, 1952), 213-17, and Nicola Bennett (London, 2000), 85-6.

34 Taylor, Taylors Travels, D1v.

35 In Works, F. Bowers (ed.) (Cambridge, 1966), vol.6.

36 Also in Works, Bowers (ed.), vol.6.

37 A presentation intended for the Prince his Highnesse on his Birth-day the 29 of May 1638 in Thomas Nabbes, Playes, Maskes, Epigrams, Elegies, and Epithalamiums (London,1639; STC 18337), F3r.

38 The Rape of Lucrece first appeared in 1608 with subsequent editions in 1609 and 1614 . The song first appears, along with 3 others added to the text, in the 1630 edition, STC 13363, E1r.

39 In Nabbes, Playes, Maskes, Epigrams, 50.

40 The Alchemist, F.H. Mares (ed.) (Manchester, 1979), 2.4.1-80, and Thomas Middleton and William Rowley, A Fair Quarrel, R.V. Holdsworth (ed.) (London, 1974), 4.1.30-41. On Abel Drugger's sign see Eric Wilson, 'Abel Drugger's Sign and the Fetishes of Material Culture' in Historicism, Psychoanalysis, and Early Modern Culture, Carla Mazzio and Douglas Trevor (eds) (London, 2000), 110-34.

41 William Haughton, An English-Men for My Money, or A pleasant comedy called, A Woman will haue her will (London, 1616; STC: 12931). As the character of Marina remarks 'We haue neuer a Signe at the dore, would not the iest proue | currant, to make the Dutchman supply that want', G2v-G3r.

42 In Ben Jonson: The Complete Masques, Stephen Orgel (ed.) (New Haven, CT, 1969), 11.122-3.

43 Ben Jonson, The New Inn, Michael Hattaway, (ed.) (Manchester, 1984), 1.1.2 n. All references are to this edition.

44 See Eric Wilson, 'Abel Drugger's Sign', 120. 